\title{
Acorn-related acquired pseudomelanosis in Calabrian black pigs
}

\author{
Giovanni Lanteri ${ }^{1 *}\left(\mathbb{D}\right.$, Jessica Maria Abbate ${ }^{1}$, Carmelo laria ${ }^{2}$, Daniele Macri ${ }^{3}$, Vincenzo Ferrantelli ${ }^{3}$ and Fabio Marino ${ }^{2}$
}

\begin{abstract}
Background: Melanosis of lymph nodes in black pigs has generally been related to regression of congenital melanoma and, occasionally, to ingestion of acorns. The aim of this manuscript is to confirm the hypothesis of a possible acquired acorn-related pseudomelanosis in the Nero Calabrese pig, a swine breed belonging to the group of Italian native breeds and whose coverage area corresponds to the region of Calabria, southern Italy. This pig is characterized by slow-growing subjects, producing, however, high quality meat suitable for the production of sausages and fine hams. The study was carried out on 142 normally slaughtered pigs. All organs were examined. Lymph nodes and intestine (jejunum) were sampled. Histochemistry was performed on deparaffinized histological sections to identify the cell types involved and to characterize the pigment stored. To further confirm the pigmentation disorder, immunohistochemistry was carried out. Total phenolic substances were identified in acorns through the use of a biochemical reaction.
\end{abstract}

Results: Lymph node pigmentation appears directly related to acorn ingestion, with a higher incidence in the group which was 70\% natural fed (acorn of Quercus virgiliana). Moreover, findings obtained revealed how different amounts of phenolic substrates present in Q. virgiliana and Q. ilex acorns can influence the incidence of such exogenous pigmentation.

Conclusion: The findings obtained in this study confirm the acquired nature of the melanin-like pigmentation detected in lymph nodes from acorn-fed swine. Acquired pigmentation must be differentiated from true melanosis as well as from melanosis related to tumor regression of congenital melanoma. This thesaurismosis can be proposed as a marker of wellbeing and quality, confirming that the pigs have been bred and fed in natural conditions.

Keywords: Acorn, Pseudomelanosis, Quercus, Swine, Thesaurismosis

\section{Background}

Pathological color modifications in tissue include a vast number of different categories; pathological pigmentations are identified as deposition of substances with a specific coloration in cells and tissues; exogenous pigments are introduced from the external environment and are stored in cells and in tissues; endogenous pigmentations are products of metabolism; thus, their appearance is due to metabolic disturbance. Endogenous pigmentations are caused by colorant substances such as lipofuscin, melanin and the group of hem pigments, derived from blood

\footnotetext{
* Correspondence: glanteri@unime.it

'Department of Veterinary Sciences, University of Messina, 98168 Messina, Italy

Full list of author information is available at the end of the article
}

pigment hemoglobin [1]. The most important and known endogenous pigmentation is melanosis, a greyblack pigmentation found in different organs due to melanin storage [2].

Melanin (in Greek melas = black), an autochthonous intracellular pigment, is characterized by a brown-black color.

It is produced by tyrosine oxidation, which represents the structural basis of its molecule, tyrosinase (with Apo enzyme containing copper) through deoxy phenylalanine (DOPA) and indolquinone. Melanin is produced by specific cells, melanocytes, whose precursors - melanoblasts (non-pigmented cells) - derive from the neural crest $[1,3]$; melanocytes can release pigment to other cells as opposed to melanophages

(C) The Author(s). 2019 Open Access This article is distributed under the terms of the Creative Commons Attribution 4.0 International License (http://creativecommons.org/licenses/by/4.0/), which permits unrestricted use, distribution, and 
and keratinocytes, which are capable of storing but not of synthetizing it [3].

Melanin production may be influenced by neuroendocrine, as well as exogenous, factors (X-rays, UV rays, arsenic, phenolic substances, etc.). Phenols can influence polymerization of quinones, derived from phenol oxidation, which assume a dark discoloration [4].

Melanin contained in melanosomes is collected from pigmented cells of the epidermis, the hair matrix, intestine mucosa and pia mater of some specific tracts of the brain (substantia nigra), and the choroid.

Several pathological modifications linked to melanin can occur: some tumors, e.g. melanoma, melanosis, acanthosis nigricans, skin anomalies in human beings, skin hyperpigmentation associated to hyperadrenocorticism, in the rare human hereditary disease known as Dubin-Johnson syndrome; in mutant Corredale sheep, in which an excretory defect of the liver produces an accumulation of melanin pigment in hepatocytes [5]. Pathological changes related to melanin can be due to a perturbation of those processes related to production, transport and dispersion of pigments [4].

Melanosis of lymph nodes in some black pigs, such as Sinclair, Duroc-Jersey, Hormel, Vietnamese pot-bellied and their cross-breeds, has also been related to regression of congenital melanoma [6-9].

In general, melanosis represents an unusual finding at the slaughterhouse [10] and to date, except in solipeds, it is not considered a disease to notify, although carcasses showing extensive melanosis are condemned. If the condition is localized, only the affected organ or part of the carcass needs to be condemned according to FAO recommendations [11]. Recent investigations, performed at slaughterhouses on the autochthone swine breed Nero Siciliano pig reared free-range (in plein-air), have shown an increased incidence of melanosis $[4,12]$.

The Nero Calabrese pig breed is characterized by slow growing subjects, producing high-quality meat suitable for the production of sausages and fine hams, with meat $\mathrm{pH}$ tending to decrease more quickly compared to the modern depigmented breeds. Monoinsature and polyinsature fatty acids of the omega- 3 and omega- 6 series are more present in the meat of the black pigs reared free range as compared to those reared intensively. Another advantage derives from the fact that animals, because of their rusticity, can be farmed free range all year and can adapt very well to any possible feed, including food derived from grazing. In such a kind of farming system, animals live in a large closed off woodland area, where they can feed on natural pabulum, generally composed of acorns, tubers, roots, etc. Commercial food is daily provided only as an integrative supplement, thus reducing the environmental impact of these foodstuffs.

The aim of the present paper was to verify the possible acquired pathogenesis for a melanin-like pigmentation in Nero Calabrese pigs, by macroscopic, histological, immuno-histochemical and biochemical exams. Moreover, considering the high frequency in the Calabrian region of holm oak and quercus acorns being used as swine feed, it was possible to demonstrate how a different phenolic substrate available in different types of acorns may influence the incidence of exogenous pigmentation.

\section{Results}

Results obtained by macroscopic and microscopic evaluation performed on pig specimens have been included in Table 1. Briefly, subjects which had been fed this food for a longer period of time/higher quantity showed the highest presence of phenolic substrate in quercus acorn and an increased incidence of the pigmentation. Moreover, groups fed with Q. virgiliana showed a greater melanosis prevalence than those fed with $Q$. ilex. On the other side, no significant different labelling was demonstrated by the histochemistry and immunohistochemistry between the different positive groups. In details: Group A (34 subjects, 70\% natural fed/present in grazing [quercus acorn "Quercus virgiliana", roots, tubers] $+30 \%$ commercial fed) showed pseudomelanosis of lymph nodes in 34/34 subjects (100\% prevalence); group B (42 subjects, $40 \%$ natural fed/present in grazing [quercus acorn "Quercus virgiliana", roots, tubers] $+60 \%$ commercial fed) showed a positivity of $36 / 42$ subjects $(85.71 \%$ ); group C (35 subjects, $70 \%$ natural fed/present in grazing [holm oak acorn "Quercus ilex", roots, tubers] $+30 \%$ commercial fed). showed a positivity of $28 / 35$ subjects (80\%); group D (31 subjects, $40 \%$ natural fed/present in grazing [holm oak acorn "Quercus ilex", roots, tubers] $+60 \%$ commercial fed) showed a positivity of 23/31 (74.19); group E (29 subjects, 100\% commercial fed) showed no pseudomelanosis (0\%). Statistical analysis highlighted a significant difference in pseudomelanosis prevalence among groups. In particular, group A (total fed with Q. virgiliana) evoked a greater pseudomelanosis prevalence than groups $B\left(x^{2}\right.$

Table 1 Prevalence of pseudomelanosis in examined subjects

\begin{tabular}{llll}
\hline & Positive & Examined & Prevalence (\%) \\
\hline GROUP A & 34 & 34 & 100 \\
GROUP B & 36 & 42 & 85.71 \\
GROUP C & 28 & 35 & 80 \\
GROUP D & 23 & 31 & 74.19 \\
GROUP E & 0 & 29 & 0 \\
\hline
\end{tabular}


$189.50 ; P<0.0001), \quad \mathrm{C}(\mathrm{\chi} 27.57 ; P=0.003), \quad \mathrm{D} \quad\left(\mathrm{\chi}^{2}\right.$ 10.01; $P=0.0008)$ and $E(X 2$ 63.00; $P<0.0001)$. Chi square test showed a significant higher pseudomelanosis prevalence in groups $\mathrm{B}\left(\mathrm{X}^{2}\right.$ 50.42; $\left.P<0.0001\right)$, C $(\mathrm{X} 241.20 ; P<0.0001)$ and $\mathrm{D}(\mathrm{X} 250.20 ; P<0.0001)$ compared to group E.

Macroscopic exam carried out on lymph nodes did not show any modification in shape and volume; the only evident feature was the strong black-brownish discoloration of the tissue which, in all the positive cases observed, involved both cortical and medullar portions (Fig. 1). None of the control animals showed any pigmentation in lymph nodes.

Histological exam performed on lymph node tissue sections stained with $H \& E$ permitted to show a macrophage infiltrate containing a granular brownish pigment from multiple observations (three independent histopathologists) (Fig. 2). Nile Blue elective staining showed a dark green pigment, differentiating it from lipofuscin and thus suggesting a diagnosis of pseudomelanosis (Fig. 3). Finally, Lillie's method for ferric and ferrous iron (Fig. 4), a highly specific reaction, showed granulation of dark green color in macrophages, providing a further and final confirmation of the diagnosis. Both the two discolorating histochemical tests specific for melanin (Melanin Bleach and Hydrogen Peroxide) revealed the total disappearance of the pigment from the lymph node tissue (Fig. 5).

Okun's reaction, performed on cryostate intestine sections (jejunum), showed formation of intracellular pseudomelanin pigment in mastocytes detected in intestinal villi (Fig. 6), confirming the presence of tyrosinase enzymes at the level of the enteric wall in swine.

No skin melanomas were detected.

The immunohistochemical reaction with macrophage marker (Fig. 7), performed on lymph node tissue sections, showed a strong cytoplasmic expression of macrophages containing variable amounts of pigment. The different concentrations checked for the anti-human melanoma antibody, as well as the immunoreaction against S-100, did not show any expression, thus excluding the hypothesis of melanoma metastasis in lymph nodes.

Results obtained from biochemical assay performed on acorn specimens showed the presence of a higher amount of phenolic substances ( $\mathrm{mg}$ of gallic acid equivalents/mg of acorn tissue) in Quercus as compared to that of holm oak (Table 2).

\section{Discussion}

Data here reported represent the first experimental evidence of a feeding related melanosis in Nero Calabrese pig. This conclusion is supported by the high incidence of melanosis in acorn fed groups the absence of neoplastic skin lesions, the absence of immunoreaction for anti-human melanoma which cross reactivity has been demonstrated by Lanteri et al. [13], the absence of such pigmentation in control animals, as well as from Okun's reaction performed on the intestinal mucosa, confirming the acorn related enteric pathogenesis. Thus, the results obtained in

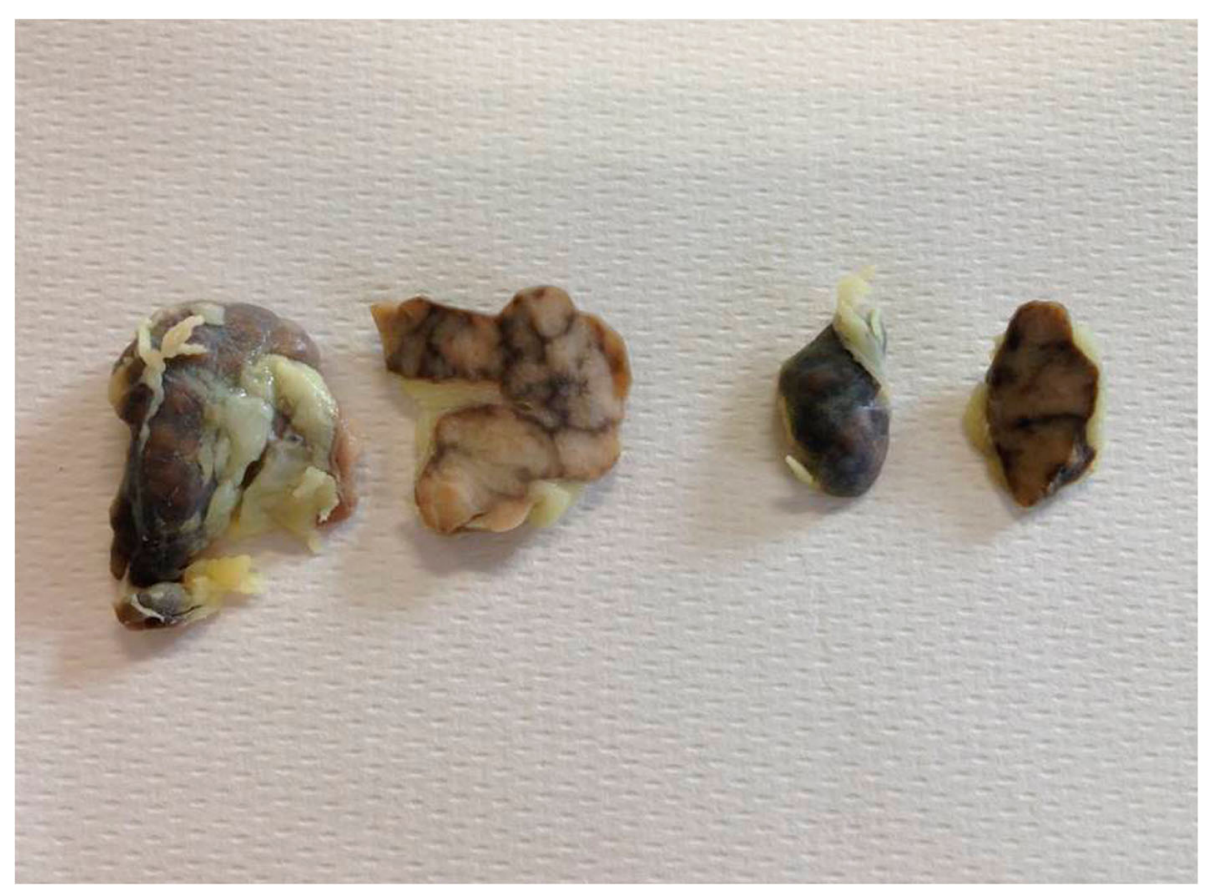

Fig. 1 Lymph nodes: Macroscopic evidence of brown-black tissue discoloration 


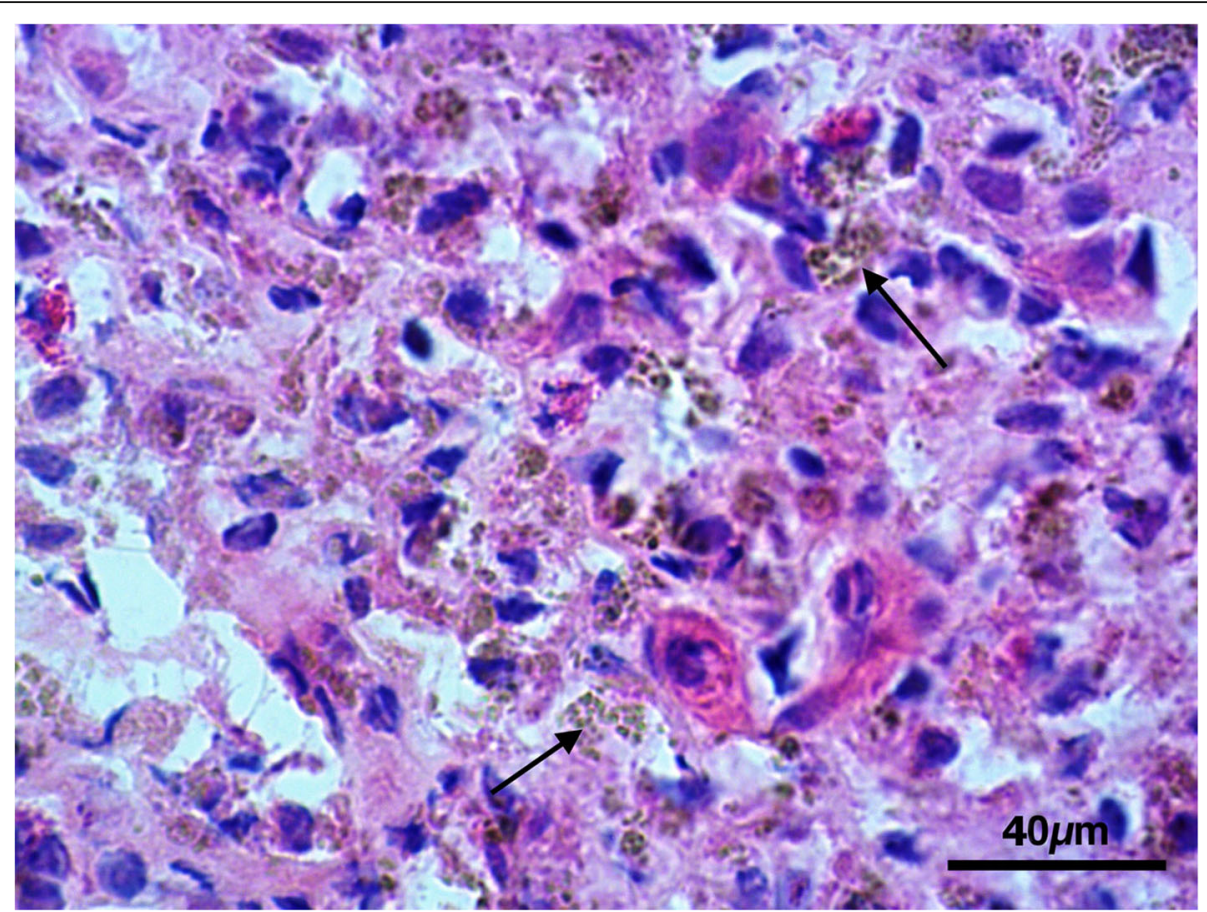

Fig. 2 Lymph nodes: Lymph node tissue sections shown a macrophage infiltrate containing a granular brownish pigment (Arrows) (H\&E)

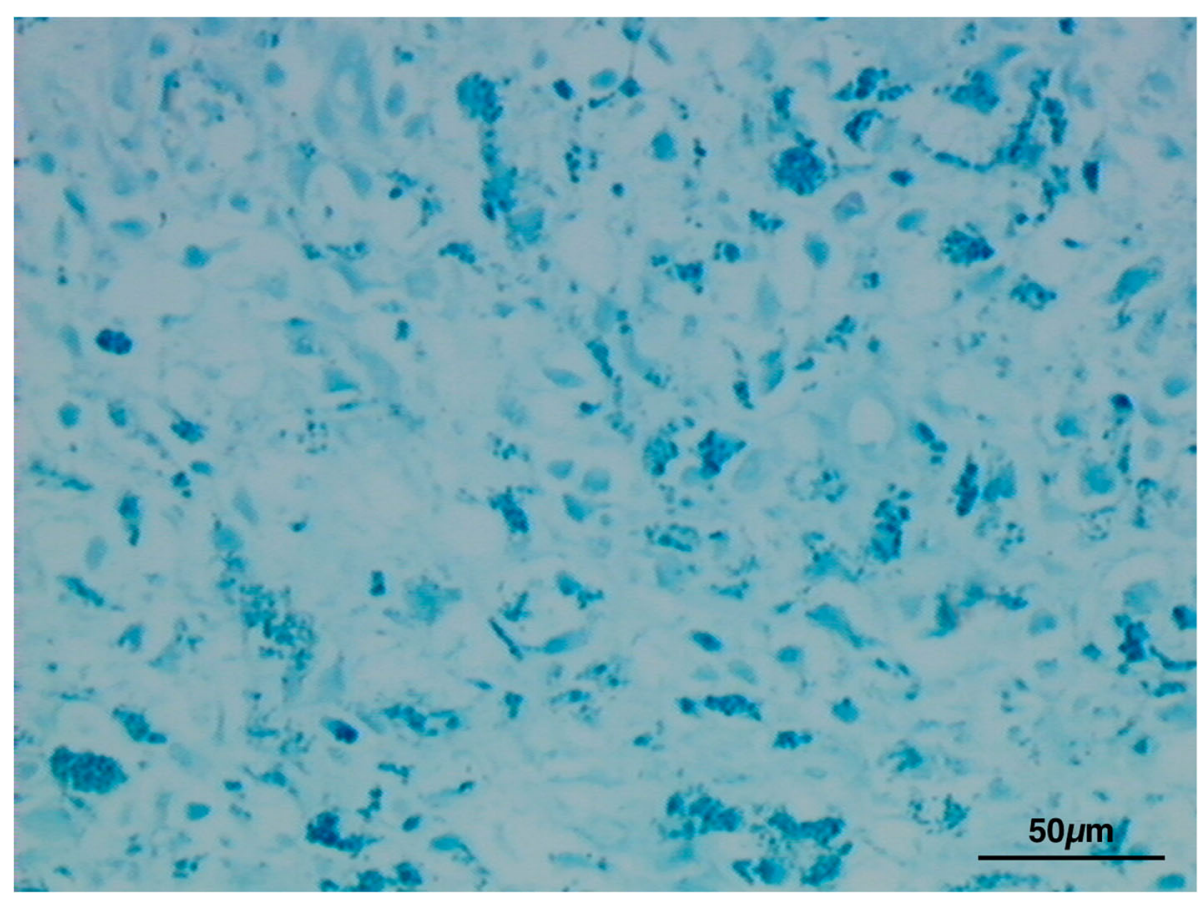

Fig. 3 Lymph nodes: Evidence of melanin pigment stained in dark green. (Nile Blue) 


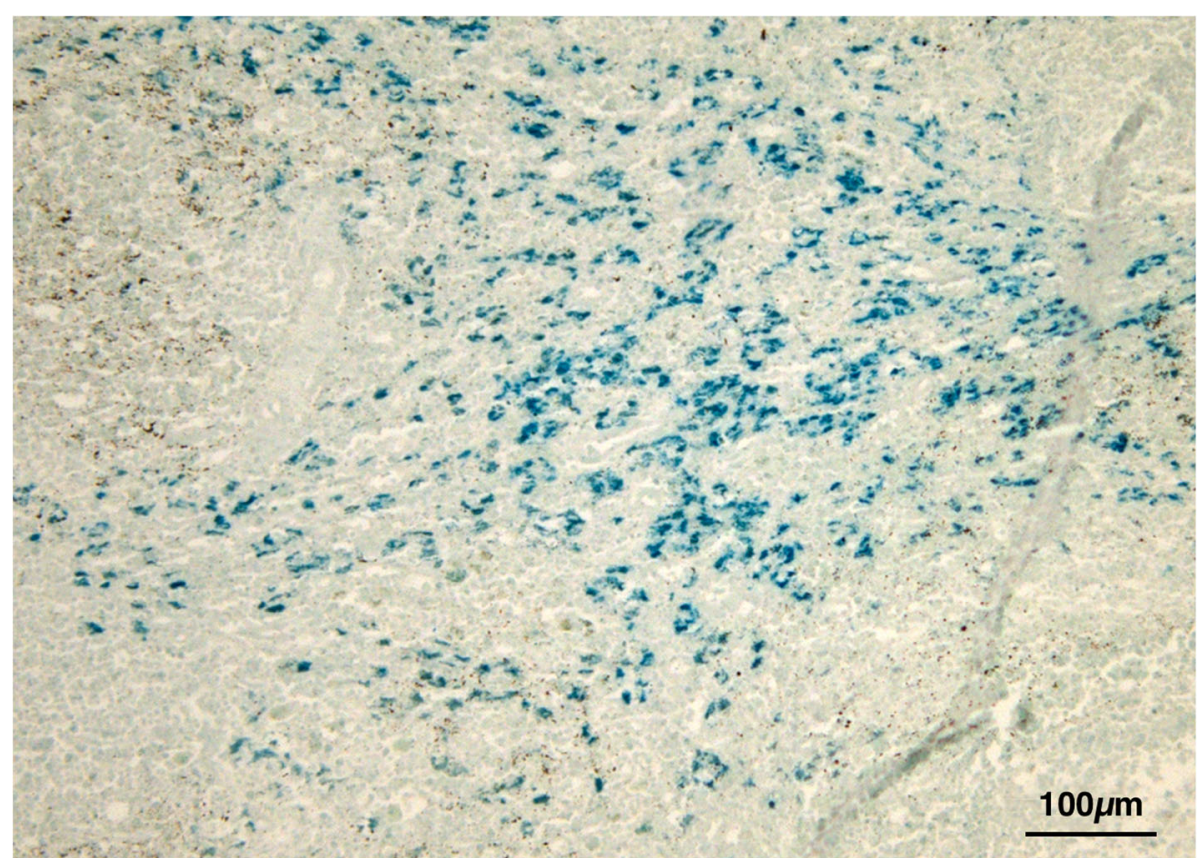

Fig. 4 Lymph nodes: Evidence of dark green granules in macrophages. (Lillie)

this study, considering the well-known process leading to melanin production, permit to hypothesize that the enzyme present at the level of the intestine in swine could start this catalytic process to form melanin, acting on the phenolic substrate of the acorn; moreover, as already shown in Table 1, the higher presence of such substrate in quercus acorn can explain the increased incidence of the pigmentation in those subjects which had been fed this food for a longer period of time/higher quantity. Moreover, groups fed

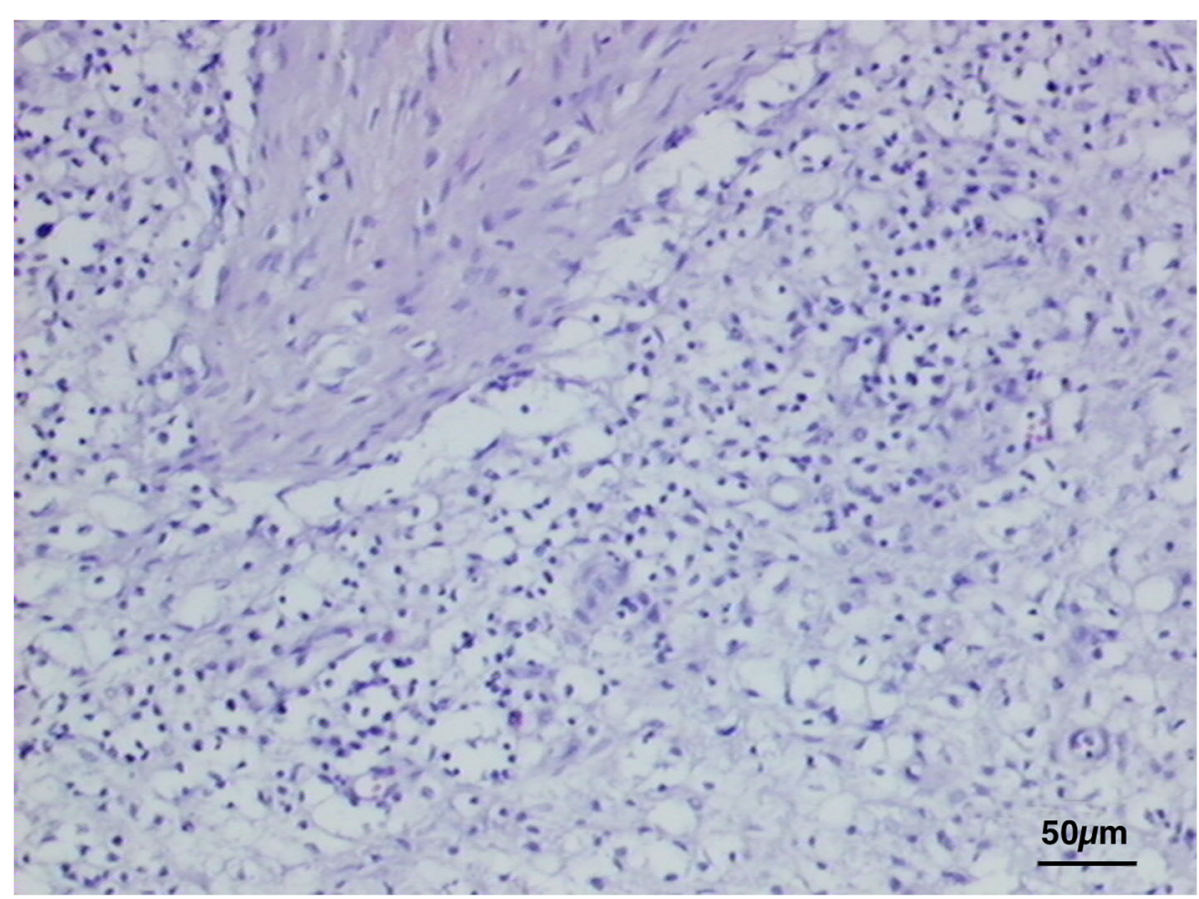

Fig. 5 Lymph nodes: Evidence of total disappearance of pigment. (Melanin Bleach) 


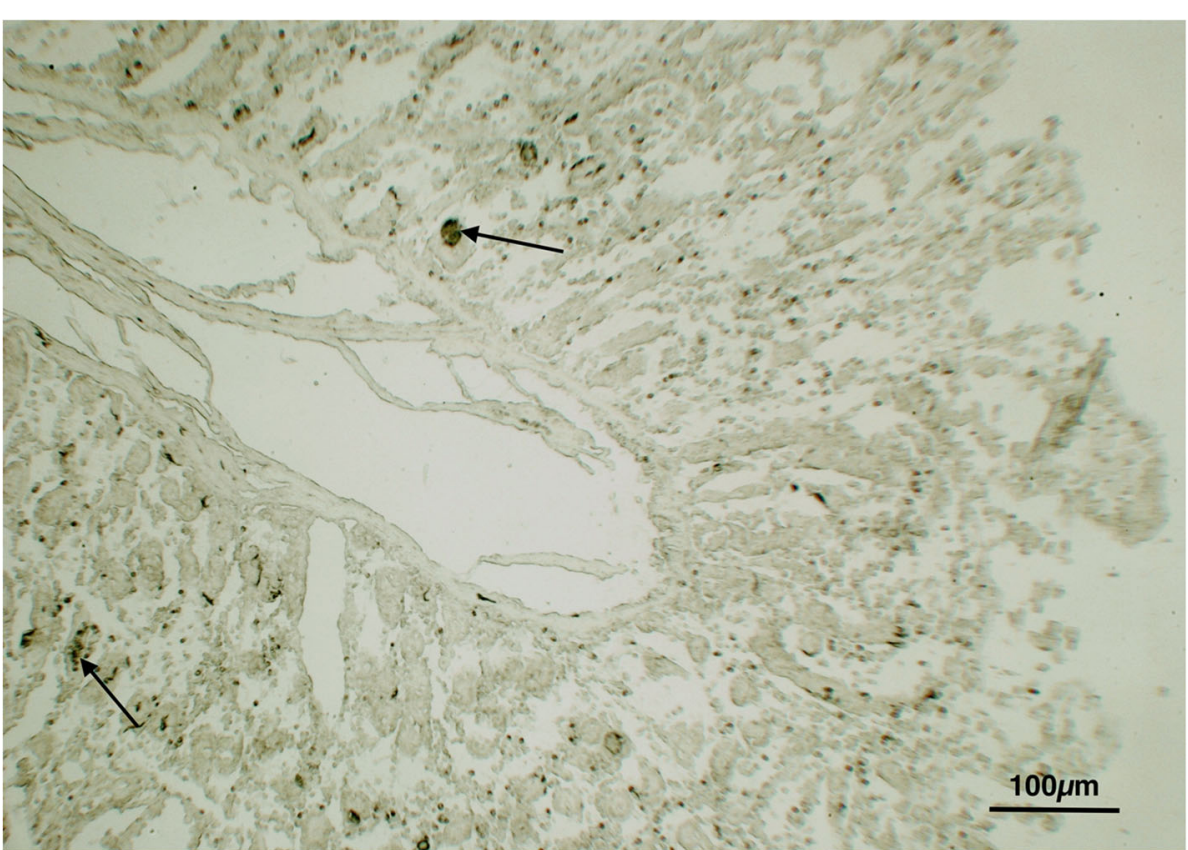

Fig. 6 Lymph nodes: Evidence of intracellular pseudomelanin pigment in mastocytes (Arrows) detected in intestinal villi confirming the presence of tyrosinase enzymes at the level of the enteric wall in swine. (Okun's reaction)

with Q. virgiliana showed a greater melanosis prevalence than those fed with $Q$. ilex.

The findings obtained support the feed-related pathogenesis previously suggested also in Nero Siciliano Pig, demonstrating for the first time acorn ingestion as cause of acquired melanosis or, rather, a pseudomelanic thesaurismosis in Nero Calabrese Pig $[4,12]$.

Nevertheless, a similar pathogenic possibility was reported as a possible origin of melanosis in pigs fed with acorns [14] even if, considering the limited scientific and

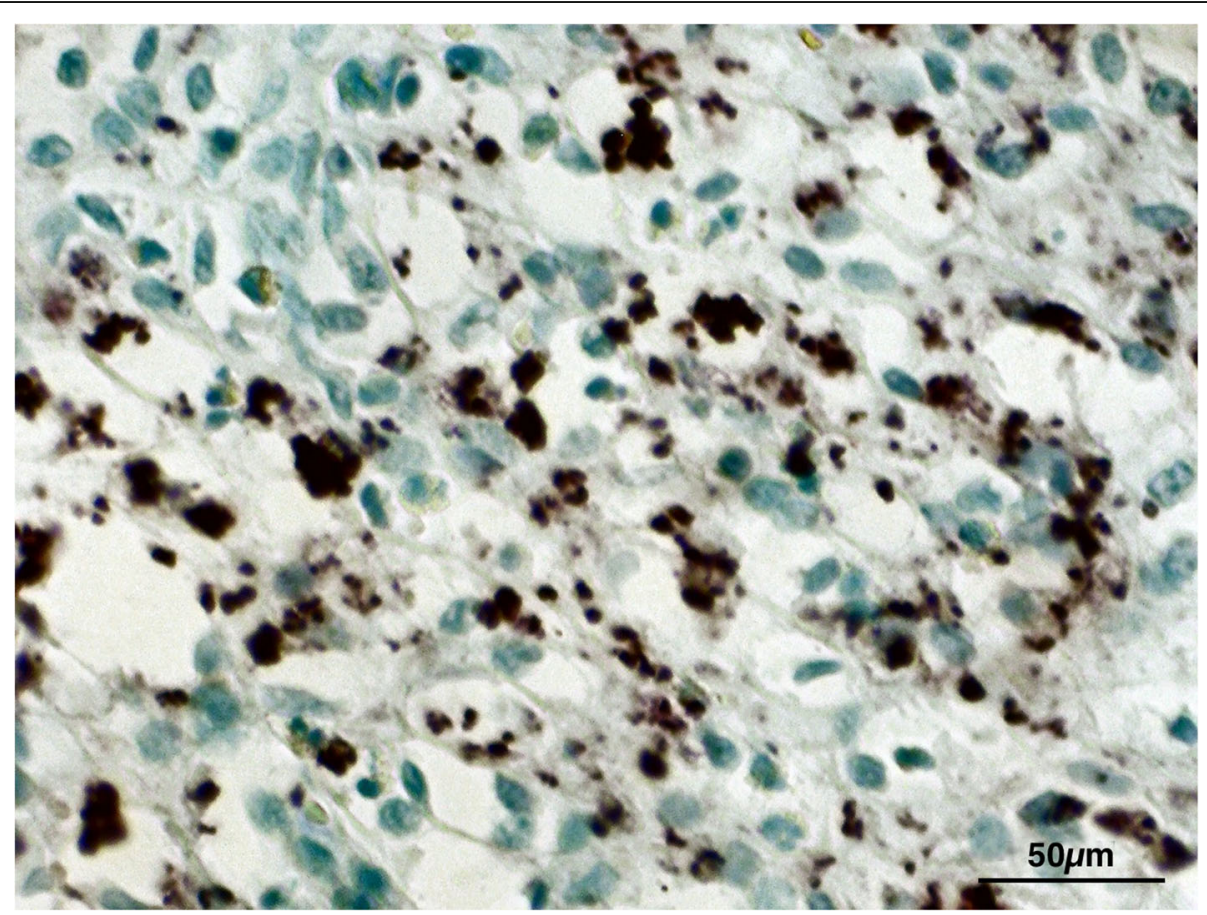

Fig. 7 Lymph nodes: Evidence of macrophages containing granular pigment. (Macrophage marker) 
Table 2 QV: Quercus virgiliana; QI: Quercus ilex

\begin{tabular}{ll}
\hline Acorn & Phenolic Substances \\
\hline QV & $0.0137 \pm 0.012 \mathrm{mg}$ \\
QI & $0.0112 \pm 0.012 \mathrm{mg}$ \\
\hline
\end{tabular}

technical knowledge at that time, tannins were only suggested as a possible cause although no demonstration was provided.

The role of polyphenol-oxydase and/or peroxydase in pig intestine in activating the phenolic substrate present in acorn, determining the catalysis reaction of the melanin-like pigment, can be stated. Wilberts et al. [15] reported the presence of a melanosis coli in swine due to ceroid pigment storage with multifactorial etiology, studying the association among oxidative damage, protein nitrification and hypovitaminosis $\mathrm{E}$ [15].

In human beings, melanosis coli is characterized by a brown-black pigmentation of the colon mucosa and is commonly associated to chronic use of anthracen based laxative (cascara, senna, aloe and rhubarb, among others), containing antrachinone as the active principle. Histologically, melanosis coli is characterized by macrophage carrying pigment in the lamina propria of the colon-rectal mucosa [16]. Recent laboratory investigations have shown that the composition of such pigment is not perfectly superimposable with melanin pigment [17]; consequently, the term pseudomelanosis was introduced, suggesting the presence of a melanin-like pigment with exogenous origin. In our opinion, the pathogenesis of the lymph node pigmentations here reported resembles that of melanosis coli, even if in our opinion the term pseudomelanosis should be preferred.

In the field of comparative pathology, the chronic use of vegetable laxatives containing anthraquinone over a long time, in man, was reported to evoke the appearance of melanosis in the colon $[17,18]$.

\section{Conclusions}

The typical characteristics of rusticity of the Nero Calabrese Pig, as well as the Sicilian breed, generally farmed in plein-air, make this swine breed an interesting in vivo model to study some disorders which have disappeared or, at least are rare, in modern swine culture, and so it could be considered as a model for comparative study also for some human pathologies.

\section{Methods}

In this study, 142 pigs belonging to the "Nero Calabrese" breed, both males and females, of about 18-24 months in age, reared in plein-air in a forest area of Aspromonte and fed with natural foods derived from the environment, with a supplement of commercial food in different percentages depending on seasonal availability in the territory were analyzed. All the animals belong to the "Strangio" farm and were selected on the basis of a total absence of melanoma lesions, such as maculae, nodules or exophytic masses; moreover, because of continuous meat production animals were randomly selected throughout the year, permitting to evaluate the effect of different acorns on lymph node discoloration. Pigs were subdivided into 5 groups and were regularly slaughtered at the public slaughterhouse of Siderno (RC), in the period 2015-16:

1) Group A: $n^{\circ} 34$ subjects, $70 \%$ natural fed/present in grazing [quercus acorn "Quercus virgiliana" (crude protein $4.2 \%$; etheric extract $2.9 \%$; crude fiber $2.6 \%$ ), roots, tubers] $+30 \%$ commercial fed (barley, field bean, maize, wheat feed, citrus fruit essential pulps, carob beans, sugar cane molasses, calcium carbonate, bi-calcic phosphate, sodium chloride. Analytic Composition: crude protein $17 \%$; etheric extract 3.4\%; crude fiber 4.6\%, ash 5.7\%).

2) Group B: 42 subjects, $40 \%$ natural fed/present in grazing [quercus acorn "Quercus virgiliana" (crude protein $4.2 \%$; etheric extract $2.9 \%$; crude fiber $2.6 \%$ ), roots, tubers] $+60 \%$ commercial fed (barley, field bean, maize, wheat feed, citrus fruit essential pulps, carob beans, sugar cane molasses, calcium carbonate, bi-calcic phosphate, sodium chloride. Analytic composition: crude protein 17\%; etheric extract 3.4\%; crude fiber $4.6 \%$, ash $5.7 \%$ ).

3) Group C: 35 subjects, $70 \%$ natural fed/present in grazing [holm oak acorn "Quercus ilex" (crude protein $4.6 \%$; etheric extract $2.8 \%$; crude fiber $2.8 \%$ ), roots, tubers] $+30 \%$ commercial fed (barley, field bean, maize, wheat feed, citrus fruit essential pulps, carob beans, sugar cane molasses, calcium carbonate, bi-calcic phosphate, sodium chloride. Analytic composition: crude protein $17 \%$; etheric extract $3.4 \%$; crude fiber $4.6 \%$, ash $5.7 \%$ ).

4) Group D: 31 subjects, $40 \%$ natural fed / present in grazing [holm oak acorn "Quercus ilex" (crude protein $4.6 \%$; etheric extract $2.8 \%$; crude fiber $2.8 \%$ ), roots, tubers] $+60 \%$ commercial fed (Composition: barley, field bean, maize, wheat feed, citrus fruit essential pulps, carob beans, sugar cane molasses, calcium carbonate, bi-calcic phosphate, sodium chloride. Analytic composition: crude protein 17\%; etheric extract 3.4\%; crude fiber 4.6\%, ash 5.7\%).

5) Group E: 29 subjects, 100\% commercial fed (barley, field bean, maize, wheat feed, citrus fruit essential pulps, carob beans, sugar cane molasses, calcium carbonate, bi-calcic phosphate, sodium chloride. Analytic composition: crude protein 
$17 \%$; etheric extract $3.4 \%$; crude fiber $4.6 \%$, ash $5.7 \%)$.

Sample size was determined on the basis of the number of pigs actually reared on the farm in a one-year period. Due to the homogeneity of the sample size in the different groups, all animals were considered for statistical evaluation.

At regular slaughtering, all organs were examined. Lymph nodes and intestine (jejunum), were sampled and photographed; parts of the tissue samples were fixed in $10 \%$ formalin solution and embedded in paraffin wax. Tissues coming from 10 specimens for each experimental group were used for histological, histochemical and immunohistochemical analysis. $5 \mu \mathrm{m}$ thick paraffin embedded sections were routinely stained with haematoxilin-eosin (H\&E).

Histochemical evaluation was performed on deparaffinized histological sections to identify the cell types involved and to characterize the pigment stored, using the following staining and bleaching methods:

\section{Histochemical staining reactions}

Nile Blue (hydrogen sulfate): elective staining method based on hydrogen sulfate specific to differentiate neutral fat and cholesterol esters from free fat acids and from phospholipids; such reaction permits to differentiate melanin pigment from lipofuscin [19]. Lillie's method: this histochemical reaction, based on ferric sulfate and potassium iron cyanide, is highly selective for melanin, showing pigment granules stained in dark green [20]. Okun's method: elective histochemistry for tyrosinase detection in intestine, through catalysis of the L-tyrosine and DL-DOPA in melanin. This reaction, performed on cryostated sections, is severely damaging for tissue sections [21]. Bleaching histochemical methods. Hydrogen peroxide: histological sections are treated for $24-48 \mathrm{~h}$ with $10 \%$ $\mathrm{H}_{2} \mathrm{O}_{2}$. After this treatment, melanin present in tissues, both externally and in macrophages, is discolored. Melanin is the only pigment that bleaches with this reaction [2]. Melanin bleach: this method is based upon the same principle of bleaching using hydrogen peroxide but using potassium permanganate and oxalic acid [2].

\section{Immunohistochemistry staining reactions}

To further confirm the pigmentation disorder, eliminating every doubt on the possible pathogenetic hypothesis of melanosis subsequent to regressive congenital melanoma, the following immunohistochemical stains were carried out on $10 \mu \mathrm{m}$ thick histological sections, developed from an Avidin-biotin complex (BioSpa, 20,143, Milano, Italy) and revealed by DAB (Diaminobenzidine, Vector Laboratories, Inc. U.S. Headquarters, Burlingame, California, USA): Macrophage marker (Novocastra, Newcastle Upon Tyne, UK, Product Code NCL-MAC387; dilution 1: 100), mouse monoclonal antibody with high specificity towards leucocyte antigens and L1 proteins, important for macrophage, monocyte and histiocyte labelling; to differentiate melanin pigmentation from immunohistochemistry labelling, sections were bleaching for $150 \mathrm{~min}$ by using $10 \% \mathrm{H} 2 \mathrm{O} 2$ in phosphate-buffered saline (PBS) at $60 \mathrm{C}^{\circ}$ as proposed by Orchard [22]. Monoclonal mouse anti-human melanoma (Dako, Denmark, Product Code M 7258; dilution 1:25, 1:50, 1:100, 1:200), specific against the Melan A antigen; this antibody, provided for use in immunocytochemistry and immunohistochemistry, permits to show antigens at $45,68,75 \mathrm{KDa}$ (positivity range known for pig) on the basis of concentration [23]. Exams were performed in duplicate with two different rates, on lymph node tissue sections. Polyclonal rabbit anti-S100 (Dako, Denmark, Product Code Z 0311; dilution 1:1000), antibody labelling normal melanocytes, Langerhans cells, histiocytes, condrocytes, adipocytes, cardiac and skeletal muscle, Schwann cells, epithelial and myoepithelial mammary cells, salivary and sweat glands, and glial cells. For each sample, negative controls were also performed by omission of primary antibody $(\mathrm{Ab})$ and substitution of primary antibody with an indifferent rabbit primary antibody (Additional files 2, 4). Moreover, melanoma tissue obtained from a Nero Siciliano Pig was used as positive control [13] (Additional files 1, 3).

\section{Biochemical reactions}

Total phenolic substances were identified from acorns through the use of a methanolic extract with FolinCiocalteau reagents [24]; data obtained revealed the total amount of phenolic substances expressed as amount of gallic acid on mg of acorn tissue.

\section{Statistical analysis}

Chi square analysis was performed to evaluate difference in pseudomelanosis prevalence among the Groups. $P$ values $<0.05$ were considered statistically significant.

Data were analyzed using statistical software Prism v. 4.00 (Graphpad Software Ldt., USA, 2003).

\section{Additional files}

Additional file 1: Melan A: positive control in melanoma from pig (bar $50 \mu \mathrm{m}$ ). (TIF $4973 \mathrm{~kb}$ )

Additional file 2: Melan A: negative control from pig lymph node, obtained by omission of the primary antibody $(A B)$ and substitution of primary antibody with an indifferent rabbit primary antibody (bar $50 \mu \mathrm{m}$ ). (TIF 3738 kb) 
Additional file 3: S100: positive control in melanoma from pig (bar $50 \mu \mathrm{m}$ ). (TIF $3470 \mathrm{~kb}$ )

Additional file 4: S100: negative control from pig lymph node, obtained by omission of the primary antibody (AB) and substitution of primary antibody with an indifferent rabbit primary antibody (bar $100 \mu \mathrm{m})$. (TIF $3500 \mathrm{~kb}$ )

\section{Abbreviations}

DAB: Diaminobenzidine; KDa: Kilodalton; DL-DOPA: D-form of Dihydroxyphenylalanine; FAO: Food and Agriculture Organization; H\&E: Haematoxylin and eosin; RC: Reggio Calabria

\section{Acknowledgments}

We would like to thank the owner and Dr. Carmelo De Stefano, the veterinarian caring for the animals and Dr. Francesca Arfuso for support in the statistical analysis.

\section{Authors' contributions}

$G L$ and FM contributed to study design and preparing the manuscript. JA contributed to the acquisition and interpretation of data. Cl, DM and VF contributed to the laboratory analysis, drafted and revised the manuscript. All authors have read and approved the manuscript.

\section{Funding}

The Authors declare that they have no received funding for this research.

\section{Availability of data and materials}

The datasets used and analyzed during the current study are available from the corresponding author on reasonable request.

\section{Ethics approval and consent to participate}

There is no need of ethical approval as the study was carried out on swine reared in different groups in the farm and normally fed with different acorns available in different seasons. All the animals were evaluated at slaughterhouse. Moreover, the Authors declare that have obtained written informed consent to use the animals in the study from the owner of the animals.

\section{Consent for publication}

Not applicable.

\section{Competing interests}

The authors declare that they have no competing interests.

\section{Author details}

'Department of Veterinary Sciences, University of Messina, 98168 Messina, Italy. ${ }^{2}$ Department of Chemical, Biological, Pharmaceutical and Environmental Sciences, University of Messina, 98166 Messina, Italy. ${ }^{3}$ Istituto Zooprofilattico Sperimentale della Sicilia, Via Gino Marinuzzi 3, 90129 Palermo, Italy.

Received: 1 March 2019 Accepted: 27 May 2019

Published online: 04 June 2019

\section{References}

1. Dämmrich K, Loppnow H. Modificazioni regressive. In: In: Stünzi H., Weiss E. (1986): Patologia Generale Veterinaria. Edizione italiana a cura di F. Guarda, Editoriali Grasso; 1986. p. 244-5.

2. Sheehan DC, Hrapchak BB. Theory and practice of histotechnology. St Louis: CV Mosby Co; 1980. p. 48.

3. Dianzani MU, Dianzani I, Dianzani U. Istituzioni di patologia generale. UTET scienze mediche; 2004

4. Lanteri G, Marino F, Liotta L, Stefano C, Macrì B. Experimentally induced melanin-like pigmentation (thesaurismosis) related to acorn ingestion in Nero Siciliano pigs. Acta Vet Hung. 2011;59:311-8.

5. Jones TC, Hunt RD, King NW. Veterinary pathology (6th edn) Williams and Wilkins. London Philadelphia. 1997:66-7.

6. Cerundolo R, Maiolino P, Roperto F, Lloyd DH, Visintin A, Maio M. Vitiligo following melanoma in Vietnamese pot-bellied pigs: gross, ultrastructural and immunological studies; 1998.
7. Hook RR Jr, Aultman MD, Adelstein EH, Oxenhandler RW, Millikan LE, Middleton CC. Influence of selective breeding on the incidence of melanomas in Sinclair miniature swine. Int J Cancer. 1979;24:668-72.

8. Oxenhandler RW, Berkelhammer J, Smith GD, Hook RR Jr. Growth and regression of cutaneous melanomas in Sinclair miniature swine. Am J Pathol. 1982;109:259.

9. Ruth GR, Horstmann JP, Lanin DR, Flynn K, Wang N, Hordinski M, et al. Spontaneous regression of cutaneous melanotic tumors in Duroc pigs. In: Proceedings of annual meeting American Association of Veterinary Laboratory Diagnosticians; 1980.

10. Zaghini L, Della Salda L, Marcato PS. Melanosi e melanomi nei suini macellati. Obiettivi e Doc Vet. 1995;16:65.

11. Herenda D, Chambers PG, Ettriqui A, Seneviratna P, da Silva TJP. Manual on meat inspection for developing countries. Food and Agriculture Organization of the United Nations [FAO] Animal Production and Health Paper 119 [monograph online]. FAO; 1994. Specific diseases of pigs: Cysticercosis (Cysticercus cellulosae) infes. 2004

12. Lanteri G, Marino F, Laganà G, Bellocco E, Barreca D, Liotta L, et al. Acquired melanosis caused by acorn ingestion in the Nero Siciliano pig. Vet Pathol. 2009:46:329-33.

13. Lanteri G, Marino F, Mazzullo G, Macrì B. Cutaneous melanoma and related melanosis of regional lymph nodes in Nero Siciliano pigs. Large Anim Rev. 2010;16:285-8.

14. Carta A. Sulla pseudomelanosi dei linfonodi di suini alimentati con ghiande. Atti Soc Ital Sci Vet. 1948;2:363-9.

15. Wilberts BL, Schwartz KJ, Gauger PC, Wang C, Burrough ER. Evidence of oxidative injury in pigs with melanosis coli. Vet Pathol. 2015;52:663-7.

16. Ghadially FN, Walley VM. Melanoses of the gastrointestinal tract. Histopathology. 1994;25:197-207.

17. Freeman HJ. "Melanosis" in the small and large intestine. World J Gastroenterol WJG 2008;14:4296.

18. A. O. L'utilizzo della fitoterapia. Utifar. 2017. https://www.utifar.it/uploads/ model_5/I_utilizzo_della_fitoterapia.pdf.

19. Lillie RD. A Nile blue staining technic for the differentiation of melanin and lipofuscins. Stain Technol. 1956:31:151-3.

20. Botticelli AR, Villani M, Angiari P, Peserico L. Meningeal melanocytoma of Meckel's cave associated with ipsilateral Ota's nevus case report. Cancer. 1983;51:2304-10.

21. Okun MR, Edelstein LM, Hamada G, Donnellan B, Or N. The role of peroxidase vs. the role of tyrosinase in enzymatic conversion of tyrosine to melanin in melanocytes, mast cells and eosinophils. J Invest Dermatol. 1970; $55: 1-12$.

22. Orchard GE. Use of heat provides a fast and efficient way to undertake melanin bleaching with dilute hydrogen peroxide. Br J Biomed Sci. 2007;64:89-91.

23. Cui J, Chen D, Misfeldt ML, Swinfard RW, Bystryn J. Antimelanoma antibodies in swine with spontaneously regressing melanoma. Pigment Cell Res. 1995:8:60-3.

24. Velioglu YS, Mazza G, Gao L, Oomah BD. Antioxidant activity and total phenolics in selected fruits, vegetables, and grain products. J Agric Food Chem. 1998:46:4113-7.

\section{Publisher's Note}

Springer Nature remains neutral with regard to jurisdictional claims in published maps and institutional affiliations.

Ready to submit your research? Choose BMC and benefit from

- fast, convenient online submission

- thorough peer review by experienced researchers in your field

- rapid publication on acceptance

- support for research data, including large and complex data types

- gold Open Access which fosters wider collaboration and increased citations

- maximum visibility for your research: over $100 \mathrm{M}$ website views per year

At $\mathrm{BMC}$, research is always in progress.

Learn more biomedcentral.com/submission 